Reviews

\title{
Hybrid Carbon Film Electrodes for Electroanalysis
}

\author{
Osamu Niwa, ${ }^{*}$ Saki Ohta, ${ }^{*}$ Shota Takahashi, ${ }^{*}$ Zixin Zhang, ${ }^{*}$ Tomoyuki Kamata, ${ }^{* *}$ Dai Kato, ${ }^{* *}$ \\ and Shunsuke SHIBA***
}

*Advanced Science Research Laboratory, Saitama Institute of Technology, 1690 Fusaiji, Fukaya, Saitama 369-0293, Japan

**Health and Medical Institute, National Institute of Advanced Industrial Science and Technology (AIST), 1-1-1 Higashi, Tsukuba, Ibaraki 305-8566, Japan

***Department of Materials Science and Biotechnology, Graduate School of Science and Engineering,

Ehime University, 3-Bunkyo-cho, Matsuyama, Ehime 790-8577, Japan

\begin{abstract}
Carbon materials have been widely used for electrochemical analysis and include carbon nanotubes, graphene, and borondoped diamond electrodes in addition to conventional carbon electrodes, such as those made of glassy carbon and graphite. Of the carbon-based electrodes, carbon film has advantages because it can be fabricated reproducibly and micro- or nanofabricated into electrodes with a wide range of shapes and sizes. Here, we report two categories of hybridtype carbon film electrodes for mainly electroanalytical applications. The first category consists of carbon films doped or surface terminated with other atoms such as nitrogen, oxygen and fluorine, which can control surface hydrophilicity and lipophilicity or electrocatalytic performance, and are used to detect various electroactive biochemicals. The second category comprises metal nanoparticles embedded in carbon film electrodes fabricated by co-sputtering, which exhibits high electrocatalytic activity for environmental and biological samples including toxic heavy metal ions and clinical sugar markers, which are difficult to detect at pure carbon-based electrodes.
\end{abstract}

Keywords Carbon film, sputter deposition, surface termination, metal nanoparticles, electroanalysis

(Received September 18, 2020; Accepted October 8, 2020; Advance Publication Released Online by J-STAGE October 16, 2020)

1 Introduction

2 Surface Terminated or Doped Carbon Film Electrodes

$2 \cdot 1$ Nitrogen terminated or doped carbon film electrodes

2.2 Fluorinated carbon film electrodes

3 Carbon Film Electrode Embedded with Metal Nanoparticles
3.1 Electrode fabrication process and structure

3.2 Electrochemical characterization and analytical applications

4 Conclusion

5 Acknowledgements

6 Supporting Information

7 References

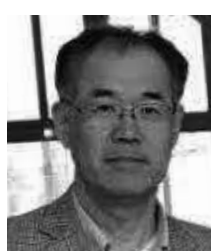

Osamu Niwa received hi B.S., M.S., and Ph.D. from Kyushu University in 1981 1983 and 1990, respectively. $\mathrm{He}$ joined the NTT Corporation in 1983 and the National Institute of Advanced Industrial Science and Technology (AIST) from 2004 to 2015. Since 2015, he is a professor at the Saitama Institute of
Technology. His research interests are electrochemical analysis, biosensor and carbon material.

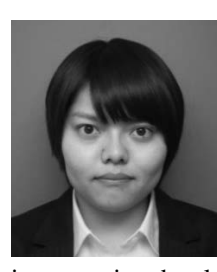

Saki OнтA received her master's degree from Saitama Institute of Technology. From 2020, she is a Ph.D. student of Graduate School of Life Science and Green Chemistry, Saitama Institute of Technology. Her research interest is development of electrode surface processing for suppress fouling by biomolecules.

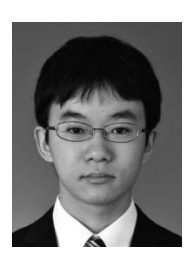
Shota Takahashi received his bachelor's degree from Saitama Institute of Technology. From 2020, he is a Master student of the Department of Life Science and Green Chemistry, Graduate School of Engineering, Saitama Institute of Technology. His research interest is the development of metal nanoparticle modified electrodes.

$\dagger$ To whom correspondence should be addressed.

E-mail: niwa@sit.ac.jp 


\section{Introduction}

In the electroanalytical chemistry field, carbon materials have been widely used because they have wider potential windows than those of other metals such as platinum and gold. Previous review articles have introduced various carbon materials used in electrochemistry. ${ }^{1,2}$ Glassy carbon (GC) electrodes have been employed for basic electrochemical measurements. In contrast, printed electrodes using carbon inks have been studied for use in practical biosensors and wearable sensing devices because of their low cost and simple fabrication process. ${ }^{3,4}$

Since the 1990s, new carbon materials have been employed by several groups. Boron-doped diamond (BDD) electrodes ${ }^{5-7}$ have a wider potential window, a lower capacitive current and low adsorption of biomolecules than other electrodes. Thanks to their superior electrochemical performance, BDD electrodes have led to an increase in the number of analytes with high oxidation or reduction potentials. ${ }^{8}$ However, BDD electrodes have mainly been formed by using plasma chemical vapor deposition (CVD) or a thermal CVD process with high deposition temperature of $400-700^{\circ} \mathrm{C}$, which has limited the available substrate materials.

More recently, various nanocarbons including carbon nanofibers, carbon nanotubes (CNT) and graphenes ${ }^{9-11}$ have been studied mainly for developing electrode materials for energy devices, since such nanocarbons have extremely large surface areas. This is also advantageous for immobilizing various biomolecules, such as enzymes, to develop sensitive biosensors ${ }^{12-14}$ and biofuel cells. ${ }^{15}$ However, their large surface area also increases the noise level when employing such electrodes for direct electrochemical measurements. In addition, the reproducible fabrication of nanocarbon electrodes is difficult because the materials have to be used after modification on solid electrodes.

In contrast, carbon films have advantages because they can be fabricated reproducibly into electrodes with a wide range of shapes and sizes. ${ }^{16}$ Various different carbon film fabrication processes have been proposed. The pyrolysis of deposited 3, 4, 9,10 -perylenetetracarboxylic dianhydride ${ }^{17,18}$ or polymer ${ }^{19,20}$ has been used to fabricate the carbon films that are applied to electrochemical measurements. In contrast, various kinds of vacuum deposition processes have been used to fabricate carbon film electrodes. These processes include radio frequency (RF) magnetron sputtering, ${ }^{21}$ electron cyclotron resonance (ECR) sputtering, ${ }^{22,23}$ electron beam evaporation, ${ }^{24}$ and a filtered cathodic vacuum arc (FCVA) system. ${ }^{25}$ We have employed ECR and unbalanced magnetron (UBM) sputtering to fabricate nanocarbon film electrodes. ${ }^{26,27}$ The film electrodes consist of both $\mathrm{sp}^{2}$ and $\mathrm{sp}^{3}$ bonds, and the $\mathrm{sp}^{3}$ content can be controlled up to around $40 \%$ by changing ion acceleration voltage. ${ }^{28}$ The carbon film has a very smooth surface ${ }^{26}$ and has a much wider potential window than GC electrodes. We have been using these films to detect DNAs, including methylated DNAs, ${ }^{29-31}$ and to detect a neurotransmitter after modifying the film with enzymes. ${ }^{32}$

Although the pure carbon film electrodes show excellent electrochemical characteristics as described above, film electrodes were required that offered improved performance such as higher electrocatalytic activity and controllable surface wettability. Doping or surface termination with other atoms or modifying the carbon electrode surface with electrocatalytic nanomaterials can be utilized to meet these requirements. In this review, we focus on two types of hybrid carbon film electrodes for application in the field of electroanalytical chemistry. The first examples are surface terminated or doped carbon film electrodes with nitrogen or fluorine atoms. We then move on to carbon film electrodes embedded or modified with metal nanoparticles (NPs) that offer improved electrochemical activity.

\section{Surface Terminated or Doped Carbon Film Electrodes}

It has been reported that the surface termination or doping of carbon materials with other atoms changes their electrochemical properties. The introduction of an oxygen containing group such as a hydroxyl group significantly changes surface wettability and has been applied when performing biochemical measurements. ${ }^{33}$ A hydrophilic surface is particularly effective in suppressing the adsorption of hydrophobic or large molecules on the electrode surface.

In contrast, Ozaki et al. reported the development of a carbon alloy that greatly reduces the overpotential of an oxygen reduction reaction (ORR) by doping carbon materials with boron and nitrogen. ${ }^{34}$ Dai et al. reported nitrogen-doped CNTs, which also exhibit high ORR activity. ${ }^{35}$ In contrast, the fluorination of carbon materials, including GC, CNTs, graphene and diamond, has been reported since fluorinated carbons provide interesting characteristics such as improved hydrophobicity and control of the surface electron transfer rate. ${ }^{36-38}$ Thanks to the above unique characteristics, surface terminated and doped carbon film electrodes have been developed mainly for electroanalytical applications.

\section{2·1 Nitrogen terminated or doped carbon film electrodes}

Several fabrication methods have been employed for nitrogen doped or terminated carbon film including pulsed laser-arc deposition, ${ }^{40-44}$ various sputtering methods, ${ }^{39,46-50}$ and CVD, ${ }^{45}$ as shown in Table 1. Yoo et al. used filtered cathodic arc and pulsed laser arc processes, respectively, to fabricate $\mathrm{N}$-containing or doped tetrahedral amorphous carbon films. ${ }^{39}$ Honda et al. reported a hydrogenated amorphous carbon film fabricated with micro-wave assisted plasma-enhanced CVD. ${ }^{46}$ Various sputter deposition methods, including $\mathrm{DC}$ magnetron, ${ }^{40} \mathrm{ECR}^{47}$ and

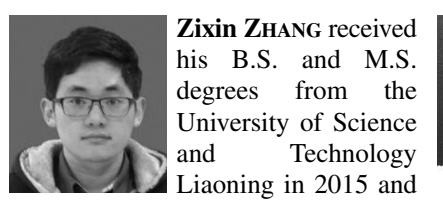

2018. Now he is a postgraduate student in the Department of Life fabrication of and Environmental Chemistry at in electrochemical application.

Saitama Institute of Technology. His

research interests are in electrochemical biosensors and nanomaterials.
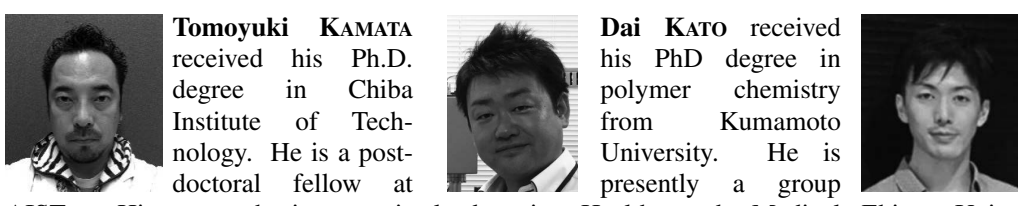

Shunsuke SHIBA received his $\mathrm{Ph} . \mathrm{D}$ degree in 2018 from University of Tsukuba. From 2019, he is an assistant professor at leader in Health and Medical Ehime University. His research Research Institute, AIST. His mainly focuses on the fabrication of research interests are in the the nano-structural electrodes for borderline field between material sensing and electrocatalytic applisciences and (electro)analytical cations.

chemistry. 
Table 1 Summary of nitrogen doped or terminated carbon film electrodes

\begin{tabular}{|c|c|}
\hline Film and fabrication process & Electroanalytical application \\
\hline $\begin{array}{l}\text { N-doped tetrahedral amorphous carbon film by } \\
\text { filtered cathodic arc }\end{array}$ & Extended potential window and electron transfer rate of some redox species ${ }^{39}$ \\
\hline $\mathrm{N}$-doped DLC by DC magnetron sputtering & ASV analysis of heavy metal ions $\left(\mathrm{Pb}^{2+}, \mathrm{Cd}^{2+}\right)^{40}$ \\
\hline \multirow[t]{5}{*}{$\begin{array}{l}\text { N-containing tetrahedral amorphous carbon film } \\
\text { by pulsed laser-arc deposition }\end{array}$} & $\begin{array}{l}\text { Wide potential window and electron transfer behavior of } \mathrm{Ru}\left(\mathrm{NH}_{3}\right)_{6}^{2+/ 3+} \text { and } \\
\mathrm{Fe}(\mathrm{CN})_{6}^{3-14-41}\end{array}$ \\
\hline & Propranole and hydrochlorothiazide oxidation in standard and synthetic biological fluid ${ }^{42}$ \\
\hline & Anodic oxidation of estrone ${ }^{43}$ \\
\hline & Flow injection analysis of norepinephrine ${ }^{44}$ \\
\hline & Flow injection analysis of tryptophan and tyrosine ${ }^{45}$ \\
\hline $\begin{array}{l}\mathrm{N} \text {-doped hydrogenated amorphous carbon films } \\
\text { by microwave- assisted plasma-enhanced CVD }\end{array}$ & Measurements of electron transfer rates for $\mathrm{Fe}^{2+/ 3+}, \mathrm{Fe}(\mathrm{CN})_{6}^{3-14}, \mathrm{Ce}^{2+/ 3+46}$ \\
\hline N-doped carbon film by ECR sputtering & $\begin{array}{l}\text { Potential window and electron transfer behavior of } \mathrm{Ru}\left(\mathrm{NH}_{3}\right)_{6}{ }^{2+3+3+} \text { and } \mathrm{Fe}(\mathrm{CN})_{6}{ }^{3-14-} \\
\text { Improved electrochemical reaction of } \mathrm{H}_{2} \mathrm{O}_{2} \text { and oligonucleotides }{ }^{47}\end{array}$ \\
\hline $\begin{array}{l}\text { N-doped carbon film by UBM sputtering } \\
\text { (1) Sputter deposited carbon by introducing }\end{array}$ & $\begin{array}{l}\text { Potential window and electron transfer behavior of } \mathrm{Fe}(\mathrm{CN})_{6}^{3-14} \text { with low } \mathrm{N} \text { concentration } \\
\text { film }^{48}\end{array}$ \\
\hline $\mathrm{Ar} / \mathrm{N}_{2} \operatorname{gas}^{48}$ & Improved electrochemical reaction of $\mathrm{H}_{2} \mathrm{O}_{2}$ and oligonucleotides \\
\hline (2) Carbon film annealed with $\mathrm{NH}_{3}$ at $300^{\circ} \mathrm{C}^{48,49}$ & $\begin{array}{l}\text { Comparison of doped and surface terminated films }\left(\mathrm{NH}_{3} \text { treatment at } 300^{\circ} \mathrm{C}\right) \text {. Influence } \\
\text { of surface nitrogen containing groups on oxygen reduction reaction, electrochemical } \\
\text { oxidation of biomolecules }{ }^{49}\end{array}$ \\
\hline \multirow[t]{2}{*}{$\begin{array}{l}\mathrm{N} \text {-doped carbon film by UBM sputtering and } \\
\text { then treated with } \mathrm{NH}_{3} \text { or } \mathrm{N}_{2} \text { plasma }\end{array}$} & $\begin{array}{l}\text { Low adsorption of protein and improved redox behavior of } \mathrm{Fe}(\mathrm{CN})_{6}^{3-4} \text { in BSA } \\
\text { containing solution }^{50}\end{array}$ \\
\hline & Low adsorption of serotonin and improved electrochemical response $\mathrm{e}^{51}$ \\
\hline
\end{tabular}

$\mathrm{UBM}^{48-51}$ sputtering, have been used to fabricate nitrogen containing carbon films. The structure of $\mathrm{N}$-containing carbon films such as the $\mathrm{sp}^{3}$ concentration can be controlled by changing the nitrogen concentration.

$\mathrm{N}$-containing carbon films exhibit unique electrochemical performance compared with pure carbon films. Several groups have reported that the potential window of carbon film electrodes is increased by increasing nitrogen concentration. . $^{39,41,47,48}$ The electrochemical activity when using $\mathrm{Ru}\left(\mathrm{NH}_{3}\right)_{6}{ }^{2+/ 3+}, \mathrm{Fe}^{2+/ 3+}$ and $\mathrm{Fe}(\mathrm{CN})_{6}{ }^{3-14-}$ have also been studied. ${ }^{39,41,46-48}$ Swain et al. reported that the resistivity decreases with increasing nitrogen concentration. They also reported that the $\Delta E$ value of $\mathrm{Fe}(\mathrm{CN})_{6}^{3-14-}$, which shows an inner sphere electron transfer, can be decreased significantly from 119 to $84 \mathrm{mV}$, and the concentration of $\mathrm{sp}^{2}$ increased from 44 to $58 \%$ by increasing the nitrogen concentration. ${ }^{41}$ However, the absolute nitrogen concentration was not evaluated since it was controlled by the $\mathrm{N}_{2}$ gas flow rate. Our group studied the effect of the nitrogen concentration on the structure and electrochemical properties of the carbon films. ${ }^{47,48}$ Unlike the results reported by Swain $e t$ al., the $\mathrm{sp}^{2}$ concentration is lower and the $\Delta E$ value of $\mathrm{Fe}(\mathrm{CN})_{6}^{3-14}$ is higher than the corresponding values for pure carbon film. The $\mathrm{sp}^{2}$ concentration decreases and the $\Delta E$ of $\mathrm{Fe}(\mathrm{CN})_{6}{ }^{3-4-}$ increases when the nitrogen concentration increases from 8.89 to $30.39 \% .{ }^{47}$ Therefore, we need to consider film with a nitrogen concentration lower than $8.89 \%$ and fabricate such films by carefully controlling the $\mathrm{N}_{2}$ gas flow rate during sputtering. ${ }^{48}$ Figure 1 shows that the variation in the $\Delta E$ of $\mathrm{Fe}(\mathrm{CN})_{6}^{3-14}$ and $\mathrm{Ru}\left(\mathrm{NH}_{3}\right)_{6}{ }^{2+/ 3+}$ depended on the nitrogen concentration. We prepared carbon films with lower nitrogen concentrations by employing UBM sputtering, which realizes a similar film structure to that formed by ECR sputtering. ${ }^{27}$ Similar to the report by Swain et al., the $\Delta E$ of $\mathrm{Ru}\left(\mathrm{NH}_{3}\right)_{6}{ }^{2+/ 3+}$ is almost unchanged at lower nitrogen concentrations less than $20 \%$ but increases significantly at concentrations exceeding $20 \%$. In contrast, the $\Delta E$ of $\mathrm{Fe}(\mathrm{CN})_{6}^{3-14-}$ decreases by incorporating nitrogen and shows its lowest value at concentrations below $9 \%$, indicating that the carbon films reported by Swain et al. might

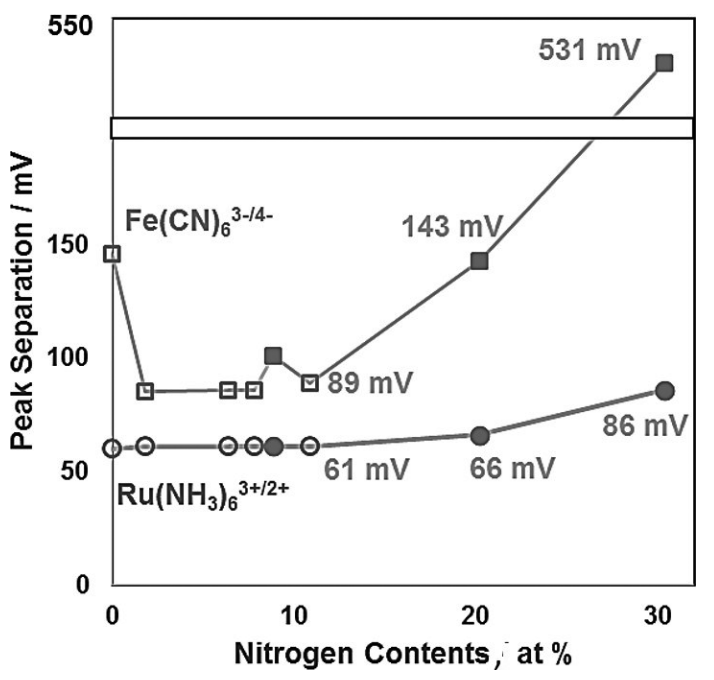

Fig. 1 Variation of $\Delta E$ for $\mathrm{Fe}(\mathrm{CN})_{6}^{3-14-}$ and $\mathrm{Ru}\left(\mathrm{NH}_{3}\right)_{6}{ }^{2+/ 3+}$ dependent on nitrogen concentration in the carbon films

contain relatively low concentrations of nitrogen.

Although the electrochemical activity of carbon films was improved by incorporating a low concentration of nitrogen, the electrochemical activity also depended upon the chemical structure of the nitrogen containing groups. As shown in Fig. 2, carbon films containing nitrogen also contain various functional groups, including graphite-like (GL), pyridine-like (PL), pyrrole-like and nitrogen-oxide structures. As regards the ORR activity, it has been reported that a carbon alloy with a larger quantity of GL structures exhibits higher ORR activity than those with a larger quantity of PL structures. ${ }^{52}$ On the other hand, several studies have demonstrated the superior activity of the PL structure in promoting ORR in nitrogen doped CNTs (N-CNT) and graphene (N-Gr). ${ }^{53,54}$ Nakamura et al. studied the ORR activity of four types of nitrogen-doped highly oriented 
pyrolytic graphite (N-HOPG) model catalysts and reported that the PL-HOPG exhibits higher ORR activity than the other HOPGs. ${ }^{55}$ Our group fabricated two types of carbon films, one rich in GL-like nitrogen-containing bonds and the other rich in PL-like bonds without changing their nitrogen concentration, $\mathrm{sp}^{2} / \mathrm{sp}^{3}$ ratio or surface flatness. ${ }^{49}$ The ORR peak potential became more positive as PL bonding increased, which was similar to previously reported results.55 Due to improved activity and the wide potential window of carbon films containing nitrogen, they have been employed for measuring biochemical and environmental samples. Zeng et al. reported the detection of $\mathrm{Pb}^{2+}$ and $\mathrm{Cd}^{2+}$, which are pollutants of drinking water. ${ }^{40}$ Swain's group has used their N-containing tetrahedral amorphous carbon film, which they obtained by pulsed laser-arc deposition, for detecting a number of analytes including norepinephrine, tryptophan and tyrosine by combining the film with a flow injection analysis (FIA) system. ${ }^{44,45}$ Figures $3 \mathrm{~A}$ and 3B show voltammograms of L-ascorbic acid and nicotinamide adenine dinucleotide (NADH) obtained with pure carbon film, PL-rich and GL-rich nitrogen containing carbon films. Pure carbon film (pure-UBM) was formed by UBM sputtering and PL-rich nitrogen containing carbon film (PL-UBM) was prepared by the $\mathrm{NH}_{3}$ treatment of pure-UBM at $300^{\circ} \mathrm{C}$. In contrast, graphite-rich nitrogen containing carbon film (GL-UBM) was prepared by UBM sputtering with the addition of $\mathrm{N}_{2}$ gas to the Ar sputtering gas. The peak potentials of both PL-UBM and GL-UBM films are lower for both L-ascorbic acid and NADH, and specifically the lowest peak potential was observed at

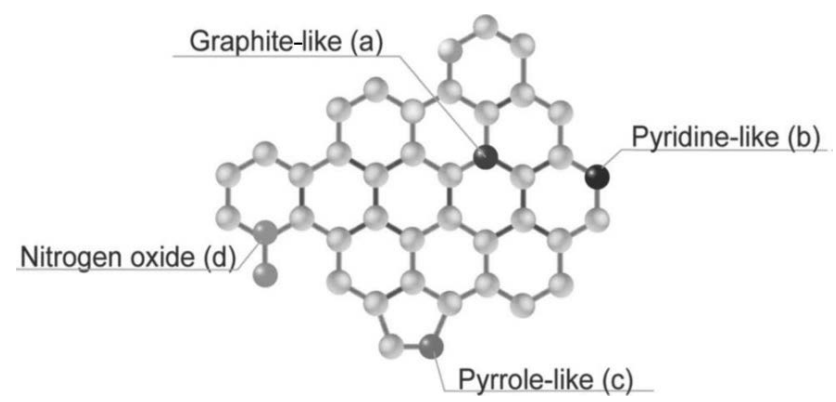

Fig. 2 Schematics of different nitrogen-containing groups. Reproduced with permission from Ref. 49.
PL-UBM. ${ }^{49}$ We also reported clear overpotential decreases when detecting mononucleotides, such as guanosine and adenosine. ${ }^{47}$

For the electrochemical measurement of biochemical samples, the biocompatibility of the sensing electrode is very important. Yasukawa $e t$ al. studied the antifouling of the electrode surface using DLC film electrodes. ${ }^{56}$ They observed no significant change in the voltammogram of $0.1 \mathrm{mM} \mathrm{Fe}(\mathrm{CN})_{6}^{3-14}$ after soaking in bovine serum albumin (BSA) solution at an oxygen plasma treated DLC film electrode. In contrast, a significant increase in the $\Delta E$ of $\mathrm{Fe}(\mathrm{CN})_{6}^{3-14-}$ was observed at the DLC without treatment. Recently, our group studied the effect of various types of plasma treatment on BSA adsorption and electrochemical response. Figure S1 (Supporting Information) compares voltammograms for $1 \mathrm{mM} \mathrm{Fe}(\mathrm{CN})_{6}{ }^{3-14}$ in the presence or absence of $100 \mathrm{mg} / \mathrm{mL}$ BSA during measurement at untreated, $\mathrm{H}_{2} \mathrm{O}$ plasma treated, and $\mathrm{NH}_{3}$ plasma treated UBM carbon film electrodes. Without treatment, $\Delta E$ increases from 0.162 to $0.843 \mathrm{~V}$ in a $0.1 \mathrm{M} \mathrm{KCl}$ solution with BSA, indicating the adsorption of BSA on the electrode surface. In contrast, $\Delta E$ increases were suppressed significantly at the electrodes with plasma treatment. In particular, the $\Delta E$ increase was negligible at the $\mathrm{NH}_{3}$ plasma treated UBM carbon film, except for the current decrease in the BSA containing solution because the diffusion coefficient in this solution decreases due to a viscosity increase. ${ }^{50}$ We also observed the suppression of serotonin adsorption after its electrochemical oxidation after $\mathrm{NH}_{3}$ plasma or $\mathrm{NH}_{3} / \mathrm{H}_{2} \mathrm{O}$ plasma treatment. ${ }^{51}$

\subsection{Fluorinated carbon film electrodes}

Compared with nitrogen containing carbon films, there are fewer reports about fluorinated carbon film electrodes. Fluorinated carbon films have been formed by magnetron sputtering and their physical properties have been reported, ${ }^{57}$ but their electrochemical characterization has not been studied. Our group treated ECR nanocarbon films with $\mathrm{CF}_{4}$ plasma, which is more stable than $\mathrm{GC}$, also after $\mathrm{CF}_{4}$ plasma treatment. ${ }^{58}$ The water contact angle increases after $\mathrm{CF}_{4}$ plasma treatment and the electron transfer rates of various redox species such as $\mathrm{Fe}^{2+/ 3+}$ and $\mathrm{Fe}(\mathrm{CN})_{6}{ }^{3-14-}$ were greatly suppressed in aqueous solutions. However, widely controllable electron transfer at fluorinated carbon film can be successfully applied to the electrode of an electrochemical biosensor. We developed an electrochemical lipopolysaccharide (LPS) sensor as shown in Fig. 4A..$^{59}$ The
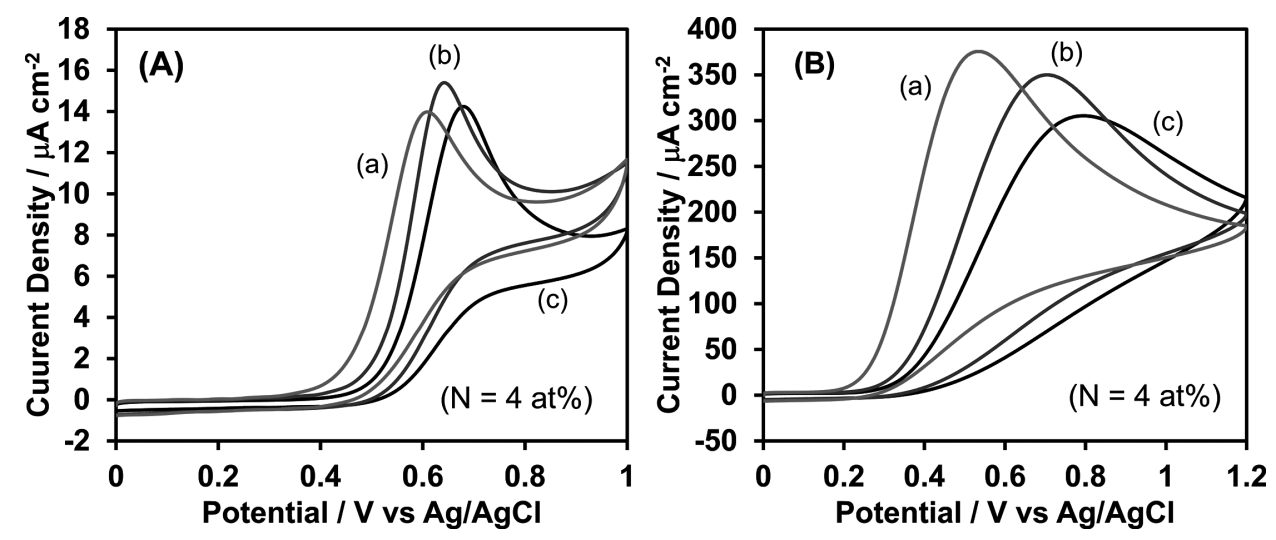

Fig. 3 Cyclic voltammograms of the (a) PL-UBM, (b) GL-UBM and (c) pure-UBM, $(N=4$ at $\%)$ electrodes for (A) $0.1 \mathrm{mM}$ NADH in $0.1 \mathrm{M}$ phosphate buffer (pH 8.2) at a scan rate of $0.01 \mathrm{~V} / \mathrm{s}$ and (B) $1.0 \mathrm{mM} \mathrm{L}$-ascorbic acid in $1.0 \mathrm{M} \mathrm{NaNO}_{3}$ at a scan rate of $0.1 \mathrm{~V} / \mathrm{s}$. Reproduced with permission from Ref. 49. 


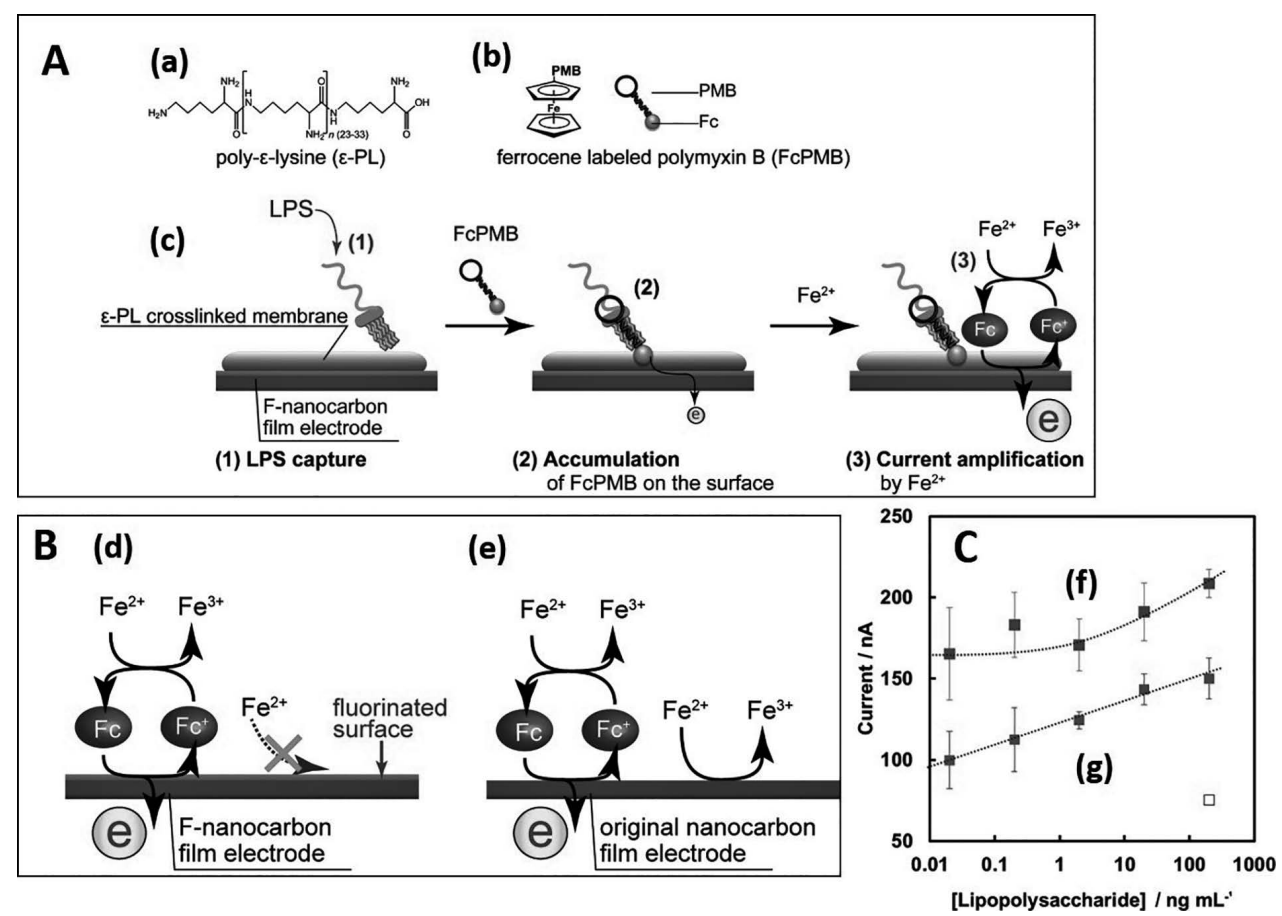

Fig. 4 A: Chemical structures of (a) poly- $\varepsilon$-lysine ( $\varepsilon$-PL) and (b) ferrocene labeled PMB (FcPMB). (c) Schematic illustration of a measurement using a combination of FcPMB and the $\varepsilon$-PL modified fluorinated nanocarbon film electrode. B: Schematic illustration of a current amplification system using (d) an fluorinated nanocarbon film electrode and (e) pure carbon film. C: Relationship between LPS concentration and obtained current at the $\varepsilon$-PL modified fluorinated nanocarbon film $(\mathrm{g})$ and the original nanocarbon film (f) electrodes. The open square indicates the obtained current of LPS $\left(200 \mathrm{ng} \mathrm{mL}^{-1}\right.$ ) at the fluorinated nanocarbon film electrode without $\mathrm{Fe}^{2+}$ ions. Reproduced with permission from Ref. 59.

fluorinated carbon film was modified with poly- $\varepsilon$-lysine ( $\varepsilon$-PL), which captures LPS, and then with ferrocene labeled polymyxin $\mathrm{B}$ (FcPMB). The redox reaction of FcPMB was enhanced in the presence of $\mathrm{Fe}^{2+/ 3+}$ by the redox cycling of FcPMB. ${ }^{59}$ Although the current increased with increasing $\mathrm{Fe}^{2+/ 3+}$ concentration, the background current also increased because $\mathrm{Fe}^{2+/ 3+}$ was directly oxidized on the electrode surface. However, the redox reaction of $\mathrm{Fe}^{2+/ 3+}$ can be suppressed at the fluorinated carbon film as shown in Fig. 4B, while maintaining sufficient electrochemical activity for FcPMB. Figure $4 \mathrm{C}$ shows the relationship between the LPS concentration and the current obtained with $\varepsilon$-PL modified fluorinated electrodes and the original nanocarbon film electrodes. The fluorinated carbon film electrode has a good linear relationship over a relatively wide concentration range compared with pure carbon film due to the suppression of the direct electrochemical reaction of $\mathrm{Fe}^{2+/ 3+}$.

Fluorinated carbon films have been used to detect lipophilic antioxidants in foods such as olive oil. Kuraya et al. employed our fluorinated carbon film electrode to detect $\alpha$-tocopherol (vitamin E) in olive oil samples by using a bicontinuous microemulsion (BME) solution and succeeded in selectively detecting lipophilic vitamin $\mathrm{E}^{60,61}$ with no interference of L-ascorbic acid, which is a well-known hydrophilic antioxidant.

\section{Carbon Film Electrode Embedded with Metal Nanoparticles}

\subsection{Electrode fabrication process and structure}

Compared with carbon electrodes, metal electrodes have advantages, including high electrochemical activity and the adsorption of heavy metal ions and thiol compounds. Metal NPs, such as platinum $(\mathrm{Pt}) \mathrm{NPs}$, have been extensively studied as a fuel cell catalyst. The high electrocatalytic activity was also advantageous when NPs were applied to electroanalysis as reviewed by Compton et al. ${ }^{62}$ They introduced silver (Ag), gold $(\mathrm{Au}), \mathrm{Pt}$, palladium $(\mathrm{Pd})$, ruthenium $(\mathrm{Ru})$, copper $(\mathrm{Cu})$ and nickel (Ni) NPs, their fabrication methods, characterization and applications. Carbon materials are widely used as electrodes to modify metal NPs. Bulk electrodes such as $\mathrm{GC}^{63}$ and nanocarbons such as $\mathrm{CNTs}^{64}$ have been modified with metal NPs. In contrast, carbon film electrodes, suitable for practical analytical devices modified with NPs have also been developed by several groups.

Various processes, including electrochemical deposition, ion implantation, and co-sputtering, have been used for fabricating carbon film electrodes modified or embedded with metal NPs. Figure 5 shows the structures of such modified electrodes. Electrochemical deposition and self-assembly deposition are simple and can be used to realize the structure shown in Fig. 5(A). The NPs are physically adsorbed on a carbon substrate with a relatively large surface area. However, the NPs sometimes detach from the carbon surface depending on the measurement condition. In contrast, carbon films embedded with NPs as shown in Fig. 5(B) can be obtained by the pyrolysis of a metal complex and polymer composite, ion implantation, and co-sputtering processes. Metal NPs are distributed inside the carbon film with some of them appearing on the surface, and they only contribute to the electrochemical reaction. Since NPs were partially embedded in the stable carbon film, NP 
(A)

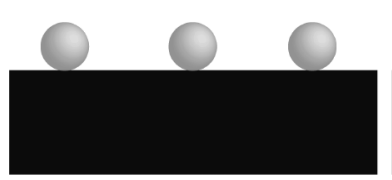

- Self assembled NPS

- Electrodeposition
(B)

(C)

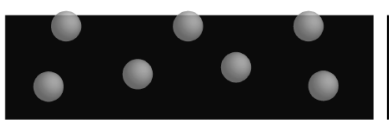

- Pyrolyzed polymer
and metal complex

- Ion implantation

- Co-sputtering of

carbon and metal

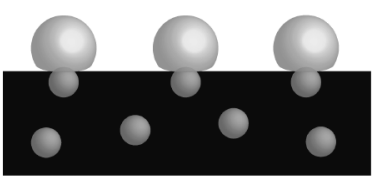

Selective electrodeposition after co-sputtering of carbon and metal

Fig. 5 Structures of carbon film electrodes modified and embedded with metal NPs (a) carbon film modified metal NPs, (b) carbon film with embedded metal NPs, (c) metal selectively deposited onto metal NPs embedded in carbon film.

Table 2 Summary of the metal nanoparticle modified film electrodes for electrochemistry

\begin{tabular}{|c|c|c|}
\hline Metals & Fabrication process & Applications \\
\hline \multirow[t]{3}{*}{$\mathrm{Pt}$} & Pyrolysis of polymer and Pt complex & Electrocatalytic reactions ${ }^{67,68}$ \\
\hline & RF-co-puttering of carbon and $\mathrm{Pt}^{69,70}$ & $\begin{array}{l}\text { Electrochemical reduction of } \mathrm{O}_{2}{ }^{69} \text { detection of } \mathrm{H}_{2} \mathrm{O}_{2} \text {, glucose by } \\
\text { enzyme modification and acetylcholine as an electrode of } \mathrm{HPLC}^{70}\end{array}$ \\
\hline & UBM co-sputtering of carbon and $\mathrm{Pt}^{71}$ & Detection of geosmin ${ }^{71}$ \\
\hline $\mathrm{Pt} / \mathrm{Ru}$ & $\begin{array}{l}\mathrm{Pt} / \mathrm{Ru} \text { incorporated N-doped DLC film by DC co-magnetron } \\
\text { co-sputtering }\end{array}$ & Potential window and voltammetric behavior ${ }^{72}$ \\
\hline \multirow[t]{2}{*}{$\mathrm{Pd}$} & Urchin-like PdNPs were electrodeposited on a CNT thin film ${ }^{73}$ & Selective detection of $\mathrm{NO}_{2}{ }^{73}$ \\
\hline & RF-co-puttering of carbon and $\mathrm{Pd}^{74}$ & Detection of $\mathrm{H}_{2} \mathrm{O}_{2}{ }^{74}$ \\
\hline \multirow[t]{6}{*}{$\mathrm{Au}$} & $\begin{array}{l}\text { Electrodeposition of Au on a carbon film using porous alumina } \\
\text { template }^{75}\end{array}$ & Structure characterization ${ }^{75}$ \\
\hline & Au deposited on BDD film electrode ${ }^{76}$ & Total inorganic As detection in water ${ }^{76}$ \\
\hline & Self-assembly deposition of AuNPs at amine-terminated BDD ${ }^{77}$ & Detection of neuraminidase $^{77}$ \\
\hline & $\begin{array}{l}\text { Electrodeposition of AuNPs on DLC films formed by filtered } \\
\text { cathodic vacuum arc deposition }\end{array}$ & Non-enzymatic detection of glucose in $\mathrm{NaOH}$ solution $^{78}$ \\
\hline & UBM co-sputtering of carbon and $\mathrm{Au}^{79}$ & $\begin{array}{l}\text { Detection of } \mathrm{As}^{3+} \text { in tap water samples by ASV and comparison } \\
\text { with ICP-MS results }\end{array}$ \\
\hline & Electrodeposited Au on the carbon film embedded with AuNPs ${ }^{66}$ & Detection of $\mathrm{Se}^{4+}$ by $\mathrm{ASV}^{66}$ \\
\hline \multirow[t]{2}{*}{ Ir } & RF-co-puttering of carbon and $\operatorname{Ir}^{81}$ & $\begin{array}{l}\text { Detection of } \mathrm{H}_{2} \mathrm{O}_{2} \text { and application to L-glutamate enzyme } \\
\text { biosensor }^{81}\end{array}$ \\
\hline & Ion implantation of Ir into BDD electrode ${ }^{82}$ & Amperometric detection of $\mathrm{As}^{3+}$ ion ${ }^{82}$ \\
\hline \multirow[t]{3}{*}{$\mathrm{Ni}$} & $\mathrm{RF}-$ co-puttering of carbon and $\mathrm{Ni}^{83}$ & $\begin{array}{l}\text { Detection of sugars by combining with HPLC and improved } \\
\text { detection limit }{ }^{33}\end{array}$ \\
\hline & $\begin{array}{l}\text { Ion beam co-sputtering employing a } 3-\mathrm{cm} \text { Kaufman ion source } \\
\text { by attaching a Ni strip to the graphite target }{ }^{84}\end{array}$ & Structure characterization (not for electrochemical analysis) $)^{84}$ \\
\hline & Electrodeposition of NiNPs onto BDD electrode ${ }^{85}$ & Detection of adenine and DNA in alkaline solution ${ }^{85}$ \\
\hline \multirow[t]{2}{*}{$\mathrm{Ni} / \mathrm{Cu}$} & $\begin{array}{l}\mathrm{UBM} \text { co-sputtering of carbon, } \mathrm{Ni} \text { and } \mathrm{Cu} \text { and changing } \mathrm{Ni} / \mathrm{Cu} \\
\text { ratio }^{86}\end{array}$ & $\begin{array}{l}\text { Improved sensitivity and stability for clinical sugar markers for } \\
\text { intestinal disease }^{86}\end{array}$ \\
\hline & & $\begin{array}{l}\text { Improved detection limit of clinical sugar markers by combining } \\
\text { with HPLC }^{87}\end{array}$ \\
\hline $\mathrm{Cu}$ & $\mathrm{RF}$-co-puttering of carbon and $\mathrm{Cu}^{88}$ & Detection of glucose in alkaline solution ${ }^{88}$ \\
\hline \multirow[t]{2}{*}{$\mathrm{Bi}$} & Electrochemical deposition of $\mathrm{Bi}^{89}$ & Determination of $\mathrm{Zn}^{2+}, \mathrm{Cd}^{2+}$ and $\mathrm{Pb}^{2+}$ by square wave $\mathrm{ASV}^{89}$ \\
\hline & Electrochemical deposition of $\mathrm{Bi}$ onto BDD electrode ${ }^{90}$ & Simultaneous determination of $\mathrm{Cd}^{2+}$ and $\mathrm{Pb}^{2+90}$ \\
\hline
\end{tabular}

detachment can be suppressed. In contrast, the surface area of NPs for an electrochemical reaction is smaller than that of NP modified electrodes. Our group has employed RF and UBM co-sputtering processes to fabricate carbon film electrodes embedded with metal NPs. Our sputtering equipment is shown schematically in Figs. S2(A) and S2(B) (Supporting Information). The RF sputtering system in Fig. S2(A) has one target system and co-sputtering was achieved by placing metal disks on the carbon target. This method was previously reported by Hayashi and Hirono et al. for fabricating carbon film embedded with magnetic cobalt (Co)NPs. ${ }^{65}$ The metal NP concentration can be controlled by changing the number of metal disks. However, this system is limited since the sputtering rate of metals is much higher than that of carbon. Figure S2(B) shows a UBM sputtering system that we are currently using to fabricate carbon films embedded with metal NPs. Since we employed a threetarget system and each target faces the substrate, two metals and carbon can be sputter deposited simultaneously and even form metal alloy NPs (nano alloy) in the carbon film. The concentrations of each metal and the carbon can be varied by changing the power of each target, and so we can control the film structure more flexibly. 

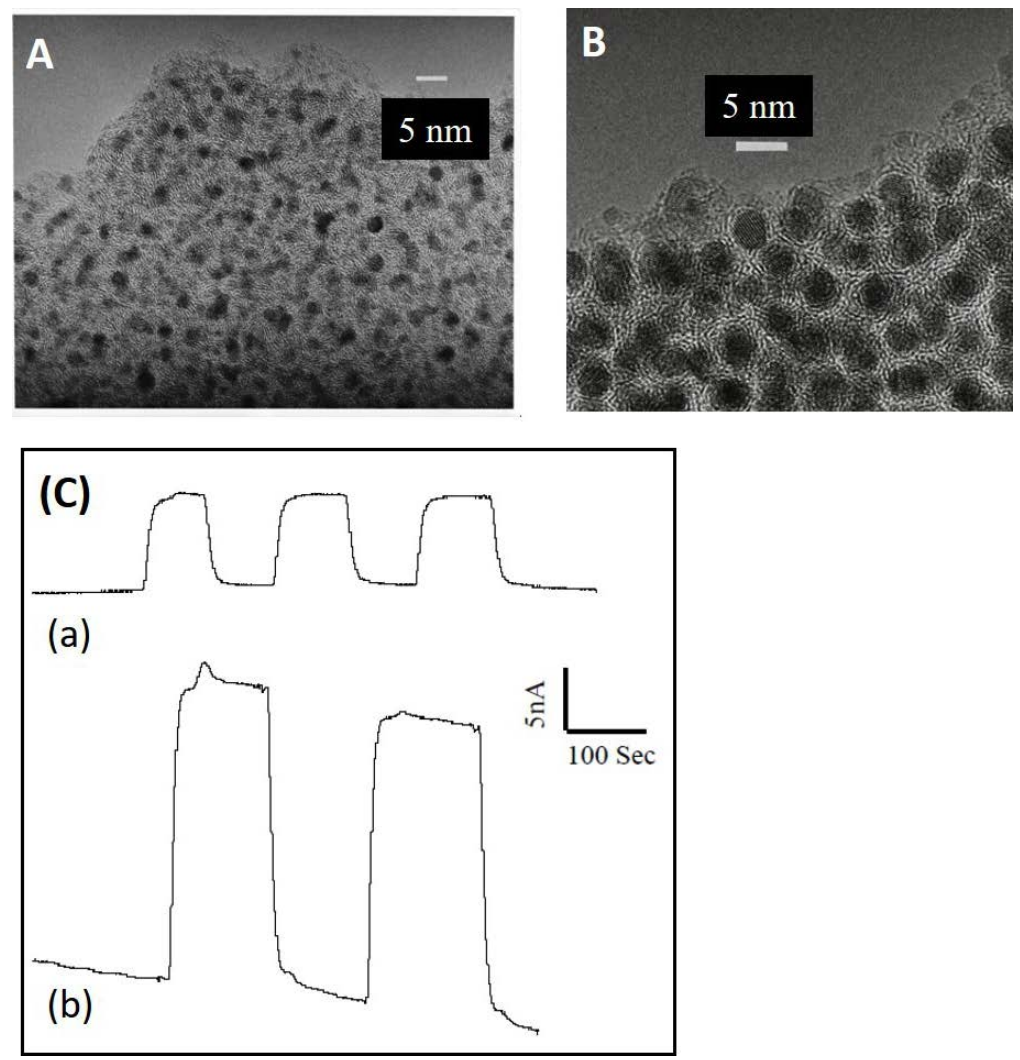

Fig. 6 TEM images of (A) PtNPs embedded (6.5\%) and (B) PdNPs embedded (7.8\%) carbon films, (C) responses of $10 \mathrm{mM}$ glucose in $0.1 \mathrm{M}$ PBS (pH 6.0) at glucose oxidase (GOx)-modified $6.5 \% \mathrm{Pt}$ NEGCF (a) and GOx-modified Pt-bulk electrodes (b), respectively. Electrode diameter, $3 \mathrm{~mm}$; application potential, $0.6 \mathrm{~V}$ versus $\mathrm{Ag} / \mathrm{AgCl}$; flow rate, $16 \mu \mathrm{L} / \mathrm{min}$. Reproduced with permission from Ref. 70.

Our group fabricated carbon film electrodes embedded with AuNPs by using UBM co-sputtering as shown in Fig. S2(B) and then selectively deposited Au only on the embedded AuNPs as shown in Fig. 5(C). This makes it possible to increase the surface area while suppressing NP detachment. ${ }^{66}$ The next section describes fabrication methods and the electroanalytical application of the modified carbon films embedded with metal NPs listed in Table 2 for each metal NP.

\subsection{Electrochemical characterization and analytical applications \\ 3.2.1 Carbon films embedded with Pt, Pd and IrNPs}

$\mathrm{Pt}$ and PdNPs have been intensively studied to develop electrodes for fuel cells by using them to modify carbon materials with a higher surface area. In contrast, film electrodes modified with PtNPs have been reported for basic studies related to fuel cell electrodes or electroanalytical applications. McCreery et al. prepared a GC like film electrode incorporating PtNPs by the pyrolysis of polymers with $\mathrm{Pt}$, characterized aspects of its structure such as PtNP size and studied electrocatalytic activity. 67,68 Our group employed RF co-sputtering as shown in Fig. S2(A) to fabricate carbon film electrodes embedded with PtNPs ${ }^{69,70}$ and PdNPs. ${ }^{74}$ Figure 6 shows TEM images of carbon film electrodes embedded with (A) PtNPs and (B) PdNPs. Since the compatibility between the noble metal and carbon is poor, PtNPs with an average diameter of $2.5 \mathrm{~nm}$ and PdNPs with an average diameter of $4.0 \mathrm{~nm}$ can be clearly observed in Figs. 6(A) and 6(B). The electrodes show high electrochemical activity for hydrogen evolution, dioxygen reduction ${ }^{69}$ and $\mathrm{H}_{2} \mathrm{O}_{2}$ oxidation. ${ }^{70}$ Figure $6(\mathrm{C})$ shows the glucose response at the glucose oxidase (GOx) modified carbon film electrodes embedded with PtNPs (above) and $\mathrm{Pt}$ bulk electrodes modified with GOx (below). A stable baseline can be obtained at the GOx modified carbon film electrode embedded with PtNPs, while the baseline decreases quickly at the Pt bulk electrode modified with GOx. In addition, the baseline current of a film electrode modified with $6.5 \%$ GOx and embedded with PtNPs is much lower than that of the Pt bulk electrode. The surface deactivation is particularly serious when we use the electrode to detect trace amounts of biochemicals, such as neurotransmitters, because it takes a long time to obtain a stable baseline current. We employed carbon film embedded with PtNPs to detect acetylcholine and choline by combining HPLC and an enzymatic reactor and obtained an improved detection limit and baseline stability compared with a Pt bulk electrode. ${ }^{70}$ We also fabricated a carbon film electrode embedded with IrNPs and achieved a low detection limit for L-glutamate, which is known to be a neurotransmitter, by modifying the electrode with glutamate oxidase. ${ }^{81}$

Carbon film electrodes embedded with PtNPs fabricated by UBM co-sputtering were employed for detecting geosmin, which is produced by certain species of fungi and blue-green algae and is known to have an earthy/musty odor. ${ }^{71}$ By applying the electrode as a detector for HPLC, an improved linear range of $0.1-1000 \mu \mathrm{g} / \mathrm{L}$ and an LOD of $100 \mathrm{ng} / \mathrm{L}$ were achieved while the $\mathrm{Pt}$ film electrode exhibited a linear range of $1-1000 \mu \mathrm{g} / \mathrm{L}$, and an LOD of $1.0 \mu \mathrm{g} / \mathrm{L}$. A co-sputtering method was also used to fabricate carbon film embedded with a metal nanoalloy by using carbon and $\mathrm{Pt}_{50} \mathrm{Ru}_{50}$ alloy targets. ${ }^{72}$ The electrodeposition of metal NPs onto carbon film electrodes 

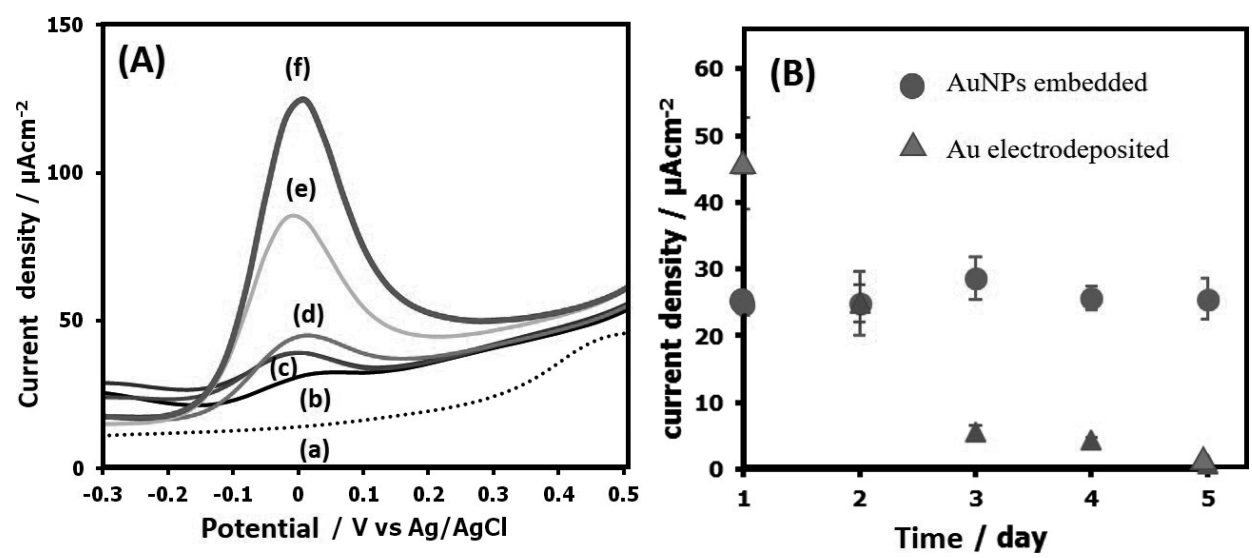

Fig. 7 (A) ASV curves for various $\mathrm{As}^{3+}$ concentrations in $0.1 \mathrm{M} \mathrm{Na}_{2} \mathrm{HPO}_{4}$ with the AuNPs embedded UBM carbon film $(\mathrm{Au}=17$ at \%) electrode. Deposition at $-0.8 \mathrm{~V} v$ s. $\mathrm{Ag} / \mathrm{AgCl}$ for $120 \mathrm{~s}$, potential scan rate of $1.5 \mathrm{~V} / \mathrm{s}$. (a) 0 , (b) 1, (c) 10, (d) 25, (e) 50, and (f) $100 \mathrm{ppb}$. (B) Stability of As measurement at the AuNPs embedded UBM carbon film ( $\mathrm{Au}=17$ at $\%$ ) and the AuNPs electrodeposited UBM carbon film electrodes. The average peak current density was obtained from repeated As measurements (3 measurements per day). ASV conditions are the same as (A). Reproduced with permission from Ref. 79.

has been reported due to its simplicity and low equipment cost. Pham et al. fabricated urchin-like PdNPs on a CNT by electrodeposition and used it for detecting $\mathrm{NO}_{2} \cdot{ }^{73}$ High electrocatalytic activity can be expected with such NPs because of their large surface area and very fine nanostructure.

\subsubsection{AuNPs embedded carbon films}

Au electrodes have been widely used for electroanalytical chemistry because various electroactive species can be modified by employing a self-assembly technique using a thiol group. ${ }^{92}$ The unique catalytic activity of AuNPs has been developed by Haruta et al. ${ }^{93}$ As shown in Table 2, several groups have reported carbon films modified with AuNPs for electroanalytical applications. Electrochemical deposition has been employed to modify carbon film with AuNPs using a porous alumina template as a mask and a unique nanostructure was realized. ${ }^{75}$ Swain et al. fabricated BDD film modified with AuNPs by electrodeposition and applied it to detect inorganic arsenic $\left(\mathrm{As}^{3+}\right)$ in real water samples by anodic stripping voltammetry (ASV) analysis. ${ }^{76}$ Unlike other metal ions, such as $\mathrm{Zn}^{2+}, \mathrm{Cd}^{2+}$ and $\mathrm{Pb}^{2+}, \mathrm{As}^{3+}$ ions cannot be preconcentrated on a carbon electrode by applying a negative potential. Au and bismuth (Bi)-based electrodes have been used because the mercury electrode, which was the most suitable and traditionally used electrode for metal ion analysis, is now avoided due to its toxicity. The BDD film electrode modified with AuNPs exhibits a detection limit of $0.005 \mathrm{ppb}$, which is lower than that of a $\mathrm{Au}$ foil electrode $(\mathrm{LOD}=0.25 \mathrm{ppb})$.

We developed carbon film embedded with AuNPs by the UBM co-sputtering of carbon and Au. Since AuNPs are embedded in the carbon film with a wide potential window, the AuNPs are more stable than that of AuNP-deposited or carbon electrodes. Figure 7(A) shows ASV results for various $\mathrm{As}^{3+}$ concentrations obtained with a UBM carbon film electrode embedded with AuNPs $(\mathrm{Au}=17$ at \%). The peak current increased linearly as the $\mathrm{As}^{3+}$ concentration increased. As a result, an LOD of $0.55 \mathrm{ppb}(S / N=3)$ and a linear dynamic range of $1-100 \mathrm{ppb}$ were obtained. This LOD is much lower than the concentration recommended by the WHO guideline $(10 \mathrm{ppb}){ }^{79}$ Figure $7(\mathrm{~B})$ shows the variation in the stripping current for repetitive measurements of $\mathrm{As}^{3+}$ when using the UBM carbon film embedded with AuNPs $(\mathrm{Au}=17$ at \%) and the UBM carbon film electrodes with electrodeposited AuNPs. The latter electrode shows a higher current at the first ASV measurement, but the current decreases significantly after 5 days. In contrast, the former electrode shows considerably superior reproducibility thanks to the embedded structure. The ASV results agreed well with those obtained by ICP-MS with tap water samples. Besides AuNP modified electrodes, electrodes modified with NPs of other metals have been used for detecting various metal ions. Einaga et al. fabricated a BDD electrode with embedded IrNPs by ion implantation and applied it to $\mathrm{As}^{3+}$ detection. ${ }^{82} \mathrm{Bi}$ electrodeposited on carbon electrodes including $\mathrm{BDD}$ were developed to detect heavy metal ions including $\mathrm{Cd}^{2+}$ and $\mathrm{Pb}^{2+} .89,90$

The beneficial effects of selenium $\left(\mathrm{Se}^{4+}\right)$ on human health have been confirmed, and they include anticancer effects and enhancement of the immune response. However, it is also known that the $\mathrm{Se}^{4+}$ concentration range between a beneficial effect and a toxic level is very narrow $(50-220 \mu \mathrm{g} /$ day $)$. Therefore, the detection of $\mathrm{Se}^{4+}$ is also important. However, preconcentration by electrochemical reduction of $\mathrm{Se}^{4+}$ is slow compared with other metal ions. We enhanced the AuNP size by the selective deposition of Au ions only on the exposed AuNP parts of carbon film electrodes with embedded AuNPs, as illustrated in Fig. 5(C), by utilizing the difference between the overpotentials of the Au and carbon surfaces. ${ }^{66}$ The SEM images and ASV results before (A and C) and after (B and D) $\mathrm{Au}$ deposition are shown in Fig. S3. Since the average size of the embedded AuNPs is less than $5 \mathrm{~nm}$ from a TEM image, the increase in AuNP size can be clearly observed and the sensitivity of $\mathrm{Se}^{4+}$ also improved. In addition to metal ion detection, AuNP modified carbon film electrodes can be used for the nonenzymatic oxidation of glucose in a strong alkaline solution. ${ }^{78}$

\subsubsection{Carbon films embedded with $\mathrm{Ni}$ and $\mathrm{CuNPs}$ and their} alloy

Au bulk electrodes have been used in HPLC to detect sugar by the pulse amperometric method. As with $\mathrm{Au}$, it is well known that $\mathrm{Ni}$ and $\mathrm{Cu}$ show high activity for oxidizing various organic chemicals in strong alkaline solution. ${ }^{94}$ The mechanism of a Ni electrode for glucose oxidation is illustrated in Fig. 8. When a positive potential is applied to the $\mathrm{Ni}$ electrode, the surface hydroxyl-groups are oxidized and form a super oxide group, 


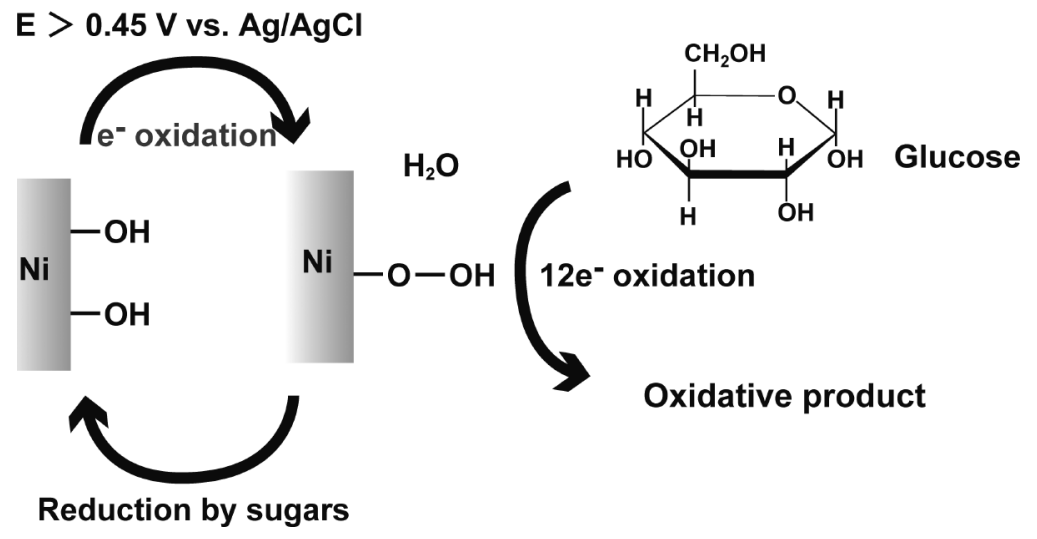

Fig. 8 The mechanism of a Ni electrode for glucose oxidation in an alkaline solution.

(A)

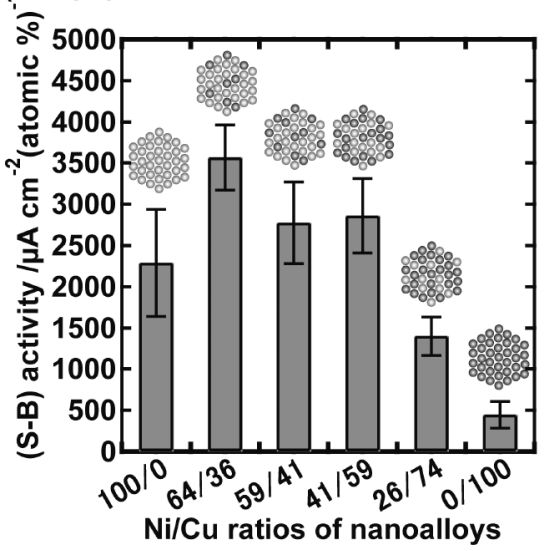

(B)

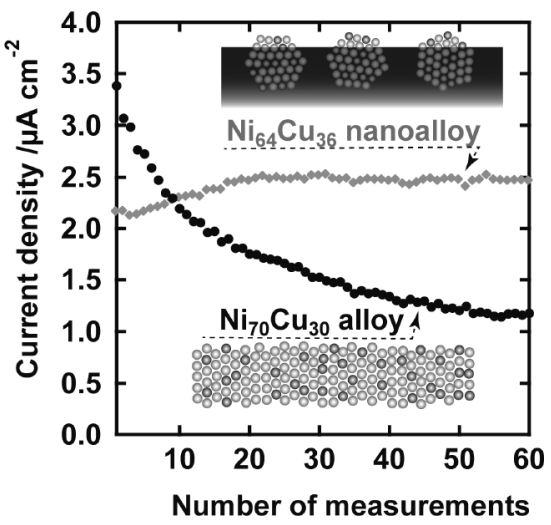

Fig. 9 (A) Electrocatalytic oxidation currents after background subtraction with various compositions of nanoalloy embedded carbon films for $500 \mu \mathrm{M}$ D-mannitol at $0.6 \mathrm{~V}(n=3)$. All the potential sweep measurements were conducted at a scan rate of $0.1 \mathrm{~V} / \mathrm{s}$. (B) Continuous flow injection analyses of $300 \mu \mathrm{M}$ D-mannitol at the $\mathrm{Ni}_{64} \mathrm{Cu}_{36}$ nanoalloy embedded carbon film and $\mathrm{Ni}_{70} \mathrm{Cu}_{30}$ alloy film electrodes using a radial flow cell. Flow rate: $0.2 \mathrm{~mL} / \mathrm{mn}$, potential $=0.5 \mathrm{~V}(v s . \mathrm{Ag} / \mathrm{AgCl})$ after $30 \mathrm{~min}$ pretreatment at $0.5 \mathrm{~V}$. Reproduced with permission from Ref. 86.

which exhibits strong oxidation activity for sugars including glucose. Our group fabricated carbon films embedded with CuNPs with different numbers of surface hydroxyl groups and found that an electrode with more surface hydroxyl groups exhibits a higher glucose oxidation current than one with fewer hydroxyl groups. ${ }^{88}$ We also compared the performance of a $\mathrm{Ni}$ bulk electrode and a carbon film electrode embedded with NiNPs when both electrodes were used to detect glucose, fructose, sucrose, and lactose as electrochemical detectors for HPLC. ${ }^{83}$ In a hydrodynamic voltammetry measurement, we found that the oxidation current of a carbon film electrode embedded with NiNPs starts to increase at $0.25 \mathrm{~V}$ (vs. $\mathrm{Ag} / \mathrm{AgCl})$, whereas it increases from $0.4 \mathrm{~V}$ at a $\mathrm{Ni}$ bulk electrode, indicating the higher electrocatalytic activity of the NiNPs embedded in the carbon film. The electrode embedded with NiNPs shows higher sensitivity for the above four sugars than a Ni bulk electrode. To improve sensitivity, we recently fabricated an electrode consisting of a $\mathrm{Ni} / \mathrm{Cu}$ nanoalloy embedded in carbon film by UBM sputtering, as shown in Fig. S2(B). Since our UBM sputtering equipment has three independent targets, the $\mathrm{Ni} / \mathrm{Cu}$ ratio in the nanoalloy and its concentration can be widely controlled by changing each target power. The carbon film embedded with $\mathrm{Ni} / \mathrm{Cu}$ nanoalloy was employed to achieve an improved detection limit for D-mannitol, which is one of the sugar biomarkers for the diagnosis of severe intestinal disease. Figure 9 (A) shows the compositional dependence of the $\mathrm{Ni} / \mathrm{Cu}$ ratios of the nanoalloy on the electrocatalytic current of $500 \mu \mathrm{M}$ D-mannitol. The electrode activity of some bimetallic nanoalloys was more pronounced than that of the corresponding monometallic NPs and bulk electrodes. We obtained the highest value with a $\mathrm{Ni} / \mathrm{Cu}$ ratio of around $64 / 36$, indicating the high electrocatalytic activity of nanoalloys. Figure 9(B) compares continuous FIA measurements of $300 \mu \mathrm{M}$ D-mannitol at a carbon film electrode embedded with $\mathrm{Ni}_{64} \mathrm{Cu}_{36}$ nanoalloy and a $\mathrm{Ni}_{70} \mathrm{Cu}_{30}$ alloy film electrode (without carbon). ${ }^{86}$ The carbon film electrode embedded with the nanoalloy provided higher stability for D-mannitol oxidation (RSD: $4.6 \%, n=60$ ) than that obtained with the alloy film electrode (RSD: 32.2\%). The signal currents of the carbon films embedded with $\mathrm{Ni}_{64} \mathrm{Cu}_{36}$ nanoalloy are larger than those of the $\mathrm{Ni}_{70} \mathrm{Cu}_{30}$ alloy films after 10 measurements in spite of the $\mathrm{Ni} / \mathrm{Cu}$ nanoalloy having a smaller area than the alloy film. Figure S4(A) shows five 
clinical sugar markers including D-mannitol and (B) shows a schematic representation of the principle for diagnosing normal and damaged intestines. When a human subject ingests five sugar markers with different molecular sizes orally, the smaller sugars easily permeate the intestinal wall. In contrast, a small amount of large sugars permeates the intestinal wall in healthy people. Therefore, the amounts of permeated sugars and the balance between large and small sugars are greatly changed at the intestinal wall of a patient. Since all sugars are nonmetabolic, intestinal diseases can be detected by measuring the amount of each sugar in a urine sample. However, a low LOD of below $1 \mu \mathrm{M}$ is required due to the low concentration of each sugar marker in the urine. Figure $\mathrm{S} 4(\mathrm{C})$ shows chromatograms obtained with carbon film electrodes embedded with $\mathrm{Ni} / \mathrm{Cu}$ nanoalloy and $\mathrm{Ni}$ bulk electrodes under constant potential application. ${ }^{87}$ Unlike commercially available Au electrodes with pulse amperometric (PAD) detection, the sensitivity and detection limit were superior to those of a Ni electrode and a $\mathrm{Au}$ electrode with PAD detection even though we conducted the experiments using normal amperometry. These results suggest that our electrode also exhibits antifouling properties with sugar samples.

Electrodes modified with NiNPs can be applied to other biomolecules. A BDD film electrode modified with NiNPs by electrodeposition was successfully applied for the detection of adenine and DNA in an alkaline solution. ${ }^{85}$

\section{Conclusions}

In this review, we introduced hybrid type carbon film electrodes for electroanalytical applications, including carbon films doped or surface terminated with other atoms, and the films modified or embedded with metal NPs. In addition to the unique properties of pure carbon films such as their wide potential window and low background noise, hybrid type carbon film electrodes offer an expanded performance range that includes surface hydrophilicity, hydrophobicity and electrocatalytic activity. In the future, various materials such as conducting metal oxides and metal organic frameworks could be successfully combined with various carbon films to create advanced functional electrodes, which will help to extend the range of measurable targets in environmental and biochemical analyses.

\section{Acknowledgements}

The authors thank Prof. Masashi Kunitake and Eisuke Kuraya for discussions about fluorinated carbon films. This work was supported by a Grant-in-Aid for Scientific Research (O. N. 17H03081 and 20K21133) from the Ministry of Education, Culture, Sports and Technology Japan, and the Saitama Prefectural Industry-Academia Collaborative Development Project Subsidy.

\section{Supporting Information}

This material is available free of charge on the Web. at http:// www.jsac.or.jp/analsci/.

\section{References}

1. R. L. McCreery, Chem. Rev., 2008, 108, 2646.
2. W. Zhang, S. Zhu, R. Luque, S. Han, L. Hu, and G. Xu, Chem. Soc. Rev., 2015, 45, 715.

3. F. E. Galdino, J. P. Smith, S. I. Kwamou, D. K. Kampouris, J. Iniesta, G. C. Smith, J. A. Bonacin, and C. E. Banks, Anal. Chem., 2015, 87, 11666.

4. K. Nagamine, A. Nomura, Y. Ichimura, R. Izawa, S. Sasaki, H. Furusawa, H. Matsui, and S. Tokito, Anal. Sci., 2020, 36, 291.

5. G. M. Swain and R. Rameshan, Anal. Chem., 1993, 65, 345.

6. R. G. Compton, J. S. Foord, and F. Marken, Electroanalysis, 2003, 15, 1349.

7. R. Tenne, K. Patel, K. Hashimoto, and A. Fujishima, J. Electroanal. Chem., 1993, 347, 409.

8. K. Yoshimi, Y. Naya, N. Mitani, T. Kato, M. Inoue, S. Natori, T. Takahashi, A. Weitemier, N. Nishikawa, T. McHugh, Y. Einaga, and S. Kitazawa, Neurosci. Res., 2011, $71,49$.

9. Y. L. Hsin, K. C. Hwang, and C.-T. Yeh, J. Am. Chem. Soc., 2007, 129, 9999

10. C. Luo. H. Xie, Q. Wang, G. Luo, and C. Liu, J. Nanomaterials, 2015, 560392

11. L. T. Qu, Y. Liu, J. B. Baek, and L. M. Dai, ACS Nano, 2010, 4, 1321.

12. Q. Xue, D. Kato, T. Kamata, Q. Guo, T. You, and O. Niwa, Analyst, 2013, 138, 6463.

13. A. Gholizadeh, S. Shahrokhian, A. Iraji zad, S. Mohajerzadeh, M. Vosoughi, S. Darbari, J. Koohsorkhi, M. Mehran, Anal. Chem., 2012, 84, 5932.

14. P. Suvarnaphaet and S. Pechprasarn, Sensors, 2017, 17, 2161.

15. T. Miyake, S. Yoshino, T. Yamada, K. Hata, and M. Nishizawa, J. Am. Chem. Soc., 2011, 133, 5129.

16. O. Niwa, Bull. Chem. Soc. Jpn., 2005, 78, 555.

17. M. L. Kaplan, P. H. Schmidt, C. H. Chen, and W. M. Walsh, Appl. Phys. Lett., 1980, 36, 867.

18. A. Rojo, A. Rosenstratten, and D. Anjo, Anal. Chem., 1986, 58, 2988.

19. S. Ranganathan and R. L. McCreery, Anal. Chem., 2001, 73, 893 .

20. M. Morita, K. Hayashi, T. Horiuchi, S. Shibano, K. Yamamoto, and K. J. Aoki, J. Electrochem. Soc., 2014, 161, H178.

21. R. Schnupp, R. Kuhnhold, G. Temmel, E. Burte, and H. Ryssel, Biosens. Bioelectron., 1998, 13, 889.

22. S. Hirono, S. Umemura, M. Tomita, and R. Kaneko, Appl. Phys. Lett., 2002, 80, 6240.

23. L. Huang, Y. Cao, and D. Diao, Electrochim. Acta, 2018, $262,173$.

24. J. J. Blackstock, A. A. Rostami, A. M. Nowak, R. L. McCreery, M. R. Freeman, and M. T. McDermott, Anal. Chem., 2004, 76, 2544.

25. H. Yu, P. Li, and J. Robertson, Diamond Relat. Mater. 2011, 20, 1020

26. O. Niwa, J. Jia, Y. Sato, D. Kato, R. Kurita, K. Maruyama, K. Suzuki, and S. Hirono, J. Am. Chem. Soc., 2006, 128, 7144.

27. T. Kamata, D. Kato, H. Ida, and O. Niwa, Diamond Relat. Mater, 2014, 49, 25.

28. J. Jia, D. Kato, R. Kurita, Y. Sato, K. Maruyama, K. Suzuki, S. Hirono, T. Ando, and O. Niwa, Anal. Chem., 2007, 79, 98.

29. D. Kato, N. Sekioka, A. Ueda, R. Kurita, S. Hirono, K. Suzuki, and O. Niwa, Angew. Chem. Int. Ed., 2008, 47, 6681.

30. D. Kato, N. Sekioka, A. Ueda, R. Kurita, S. Hirono, K. Suzuki, and O. Niwa, J. Am. Chem. Soc., 2008, 130, 3716.

31. D. Kato, K. Goto, S. Fujii, A. Takatsu, R. Kurita, S. Hirono, and O. Niwa, Anal. Chem., 2011, 83, 7595.

32. N. Sekioka, D. Kato, R. Kurita, S. Hirono, and O. Niwa, Sens. Actuators, B, 2008, 129, 442. 
33. N. Sekioka, D. Kato, A. Ueda, T. Kamata, R. Kurita, A. Umemura, S. Hirono, and O. Niwa, Carbon, 2008, 46, 1918.

34. J. Ozaki, T. Anahara, N. Kimura, and A. Oya, Carbon, 2006, 44, 3358.

35. K. P. Gong, F. Du, Z. H. Xia, M. Durstock, and L. M. Dai, Science, 2009, 323, 760.

36. T. Nakajima, M. Koh, R. N. Singh, and M. Shimada, Electrochim. Acta, 1999, 44, 2879.

37. V. N. Khabashesku, W. E. Billups, and J. L. Margrave, Acc. Chem. Res., 2002, 35, 1087.

38. E. Silva, A. C. Bastos, M. Neto, and A. J. Fernandes, Sens. Actuators, B, 2014, 204, 544.

39. K. Yoo, B. Miller, R. Kalish, and X. Shi, Electrochem. Solid-State Lett., 1999, 2, 233.

40. A. Zeng, E. Liu, S. N. Tan, S. Zhang, and J. Cao, Electroanalysis, 2002, 14, 1294.

41. X. Yang, L. Haubold, G. DeVivo, and G. M. Swain, Anal. Chem., 2012, 84, 6240.

42. B. C. Lourencao, T. A. Silva, O. Fatibello-Filho, and G. M. Swain, Electrochim. Acta, 2014, 143, 398.

43. R. F. Brocenschi, R. C. Rocha-Filho, L. Li. and G. M. Swain, J. Electroanal. Chem., 2014, 712, 207.

44. D’N Hamblin, J. Oiu, L. Haubold, and G. M. Swain, Anal. Methods, 2015, 7, 4481.

45. R. Jarosova, J. Rutherford, and G. M. Swain, Analyst, 2016, $141,6031$.

46. Y. Tanaka, M. Furuta, K. Kuriyama, R. Kuwabara, Y. Katsuki, T. Kondo, A. Fujishima, and K. Honda, Electrochim. Acta, 2011, 56, 1172.

47. T. Kamata, D. Kato, S. Hirono, and O. Niwa, Anal. Chem., 2013, 85, 9845.

48. T. Kamata, D. Kato, S. Hirono, and O. Niwa, Anal. Sci., 2015, 31, 651 .

49. T. Kamata, D. Kato, and O. Niwa, Nanoscale, 2019, 11, 10239.

50. S. Ohta, S. Shiba, T. Yajima, T. Kamata, D. Kato, and O. Niwa, J. Photopolym. Sci. Technol, 2019, 32, 523.

51. S. Ohta, S. Shiba, T. Yajima, and O. Niwa, Electrochemistry, 2020, $88,387$.

52. H. Niwa, K. Horiba, Y. Harada, M. Oshima, T. Ikeda, K. Terakura, J.-i. Ozaki, and S. Miyata, J. Power Sources, 2009, 187, 93.

53. L. Qu, Y. Liu, J.-B. Baek, and L. Dai, ACS Nano, 2010, 4, 1321.

54. L. Lai, J. R. Potts, D. Zhan, L. Wang, C. K. Poh, C. Tang, H. Gong, Z. Shen, J. Lin, and R. S. Ruoff, Energy Environ. Sci., 2012, 5, 7936

55. D. Guo, R. Shibuya, C. Akiba, S. Saji, T. Kondo, and J. Nakamura, Science, 2016, 351, 361.

56. T. Goto, T. Yasukawa, K. Kanda, S. Matsui, and F. Mizutani, Anal. Sci., 2011, 27, 91.

57. M. Ishihara, M. Suzuki, T. Watanabe, T. Nakamura, A. Tanaka, and Y. Koga, Diamond Relat. Mater, 2005, 14, 989.

58. A. Ueda, D. Kato, N. Sekioka, T. Kamata, R. Kurita, H. Uetsuka, Y. Hattori, S. Hirono, S. Umemura, and O. Niwa, Carbon, 2009, 47, 1943.

59. A. Oda, D. Kato, K. Yoshioka, M. Tanaka, T. Kamata, M. Todokoro, and O. Niwa, Electrochim. Acta, 2016, 197, 152.

60. E. Kuraya, S. Nagatomo, K. Sakata, D. Kato, O. Niwa, T. Nishimi, and M. Kunitake, Anal. Chem., 2015, 87, 1489.

61. E. Kuraya, S. Nagatomo, K. Sakata, D. Kato, O. Niwa, T. Nishimi, and M. Kunitake, Anal. Chem., 2016, 88, 1202.

62. F. W. Campbell and R. G. Compton, Anal. Bioanal. Chem., 2010, 396, 241.
63. X. Dai, O. Nekrassova, M. E. Hyde, and R. G. Compton, Anal. Chem., 2004, 76, 5924.

64. S. Shahrokhian and S. Rastgar, Electrochim. Acta, 2012, $78,42$.

65. T. Hayashi, S. Hirono, M. Tomita, and S. Umemura, Nature, 1996, 381, 772.

66. S. Shiba, S. Takahashi, T. Kamata, H. Hachiya, D. Kato, and O. Niwa, Sens. Materials, 2019, 31, 1135.

67. N. L. Pocard, D. C. Alsmeyer,. R. L. McCreery, T. X. Neeman, and M. R. Callstrom, J. Am. Chem. Soc., 1992, $114,769$.

68. H. D. Hutton, N. L. Pocard, C. Alsmeyer, O. J. A. Schueller, R. J. Spontak, M. E. Huston, W. Huang, W. Huang, R. L. McCreery, T. X. Neeman, and M. R. Callstrom, Chem. Mater, 1993, 5, 1727.

69. T. You, O, Niwa, T. Horiuchi, M. Tomita, Y. Iwasaki, Y. Ueno, and S. Hirono, Chem. Mater, 2002, 14, 4796.

70. T. You, O, Niwa, M. Tomita, and S. Hirono, Anal. Chem., 2003, 75, 2080.

71. T. Kamata, M. Sumimoto, S. Shiba, R. Kurita, O. Niwa, and D. Kato, Nanoscale, 2019, 11, 8845.

72. N. W. Khun and E. Liu, Electroanalysis, 2009, 21, 2590.

73. X.-H. Pham, C. A. Li, K. N. Han, B.-C. H.-Nguyen, T.-H. Le, E. Ko, J. H. Kim, and G. H. Seong, Sens. Actuators, B, 2014, 193, 815.

74. O. Niwa, D. Kato, R. Kurita, T. You, Y. Iwasaki, and S. Hirono, Sens. Materials, 2007, 19, 225.

75. Y. Chen, A. Yamaguchi, T. Atou, K. Morita, and N. Teramae, Chem. Lett., 2006, 35, 1352.

76. Y. Song and G. M. Swain, Anal. Chem., 2007, 79, 2412.

77. W. T. Wahyuni, T. A. Ivandini, E. Saepudin, and Y. Einaga, Anal. Biochem., 2016, 497, 68.

78. A. Liu, E. Liu, G. Yang, N. W. Khun, and W. Ma, Pure Appl. Chem., 2010, 82, 2217.

79. D. Kato, T. Kamata, D. Kato, H. Yanagisawa, and O. Niwa, Anal. Chem., 2016, 88, 2944.

80. S. Shiba, S. Takahashi, T. Kamata, H. Hachiya, D. Kato, and O. Niwa, Sens. Materials, 2019, 31, 1135.

81. T. You, O. Niwa, R. Kurita, Y. Iwasaki, K. Hayashi, K. Suzuki, and S. Hirono, Electroanalysis, 2004, 16, 54.

82. T. A. Ivandini, R. Sato, Y. Makide, A. Fujishima, and Y. Einaga, Anal. Chem., 2006, 78, 6291.

83. T. You, O. Niwa, Z. Chen, K. Hayashi, M. Tomita, and S. Hirono, Anal. Chem., 2003, 75, 5191.

84. G. Abrasonis, M. Krause, A. Mucklich, K. Sedlackova, G. Radnoczi, U. Kreissig, A. Kolitsch, and W. Moller, Carbon, 2007, 45, 2995.

85. J. C. Harfield, K. E. Toghill, C. B. McAuley, C. Downing, and R. G. Compton, Electroanalysis, 2011, 23, 931.

86. S. Shiba, D. Kato, T. Kamata, and O. Niwa, Nanoscale, 2016, 8, 12887,

87. S. Shiba, R. Maruyama, T. Kamata, D. Kato, and O. Niwa, Electroanalysis, 2018, 30, 1407.

88. T. You, O. Niwa, M. Tomita, H. Ando, M. Suzuki, and S. Hirono, Electrochem. Commun., 2002, 4, 468.

89. R. Pauliukaite and C. M. A. Brett, Electroanalysis, 2005, 17, 1354.

90. K. E. Toghill, G. G. Wildgoose, A. Moshar, C. Mulcahy, and R. G. Compton, Electroanalysis, 2008, 20, 1731.

91. M. Antonopoulou, E. Evgenidou, D. Lambropoulou, and I. Konstantinou, Water Res., 2014, 53, 215.

92. K. Uosaki, Y. Sato, and H. Kita, Langmuir, 1991, 7, 1510.

93. M. Haruta, Faraday Discuss., 2011, 152, 11.

94. P. Luo, S. V. Prabhu, and R. P. Baldwin, Anal. Chem., 1990, 62, 752 . 